\title{
ACQUISITION OF L2 ENGLISH MORPHOLOGY A FAMILY CASE STUDY
}

\author{
Yanyin Zhang, University of Canberra \\ Yanyin Zhang is a senior lecturer in TESOL and Applied Linguistics at the Univer- \\ sity of Canberra. She teaches a range of subjects such as Language Acquisition, \\ Research Projects in Language Teaching and Learning, Study of Language, Lan- \\ guage Testing, etc. Her research interests focus on second language acquisition \\ (Chinese and English), language pedagogy, and interlanguage pragmatics. She is \\ also editor (with John DeFrancis) of the ABC English-Chinese Chinese-English \\ Dictionary (University of Hawaii Press, 2010). \\ Ima Widyastuti, University of Canberra \\ Ima Widyastuti is a scholarship holder and postgraduate student in the MA TESOL \\ program at the University of Canberra. She is a lecturer in the Diploma Program \\ in Economics and Business, Gadjah Mada University, Indonesia. Her research in- \\ terest is in language pedagogy and second language acquisition. She intends to \\ pursue a career in academia and journalism.
}

This study investigates the status of morphology in the L2 English of three members of a family from Indonesia (parents and their 5-year-old daughter) who have lived, studied or worked in Australia for a year. The investigation is contextualized against various learning settings in which the informants have learned English: formal instruction in the foreign language environment, naturalistic learning in the target language setting, and a mixture of formal and naturalistic learning in the target language environment. Following the developmental hierarchy for English morphology (Pienemann, 2005; Bettoni and Di Biase, forthcoming) and analytical procedures in Processability Theory (Pienemann, 1998, 2005), we found the informants were at different stages of L2 English morphology, with the father being the most advanced and the daughter the least. We also found a systematic developmental profile of each informant in line with the developmental hierarchy for English morphology. Both findings are discussed with reference to the developmental sequences and the role of learning settings in SLA.

\section{INTRODUCTION}

Unlike native language learners, second language learners (L2ers) vary in age, motivation, learning styles and prior language learning experience. They learn the L2 in different settings: external L2 settings where the L2 is not the medium of communication in the society and is learned formally in the classroom; dominant L2 settings where the target 
language is the 'native language of the majority of the population and used in all domains in everyday life' (Siegel, 2003, p. 179). The latter consists of formal classroom instruction and naturalistic acquisition through immersion. Often, L2 learning takes place in more than one setting either simultaneously (e.g. naturalistic and formal learning in the dominant L2 setting), or at different times (e.g. formal learning in the home country followed by immersion in the target language environment). Although there is a large body of SLA research in each of these areas, few studies look into the family as the object of study. In an L2 family, the variety of variables mentioned above exists simultaneously, for example, there is a mix of learners (adults, children) at varying L2 proficiency levels with varying L2 learning backgrounds (instructed and naturalistic) and motivations. Family members also have many things in common, for example, they speak the same language(s) at home, they arrive in the target language country either together or shortly following each other. Studying the L2 learning processes and outcomes of a family would complement studies that look into certain aspect(s) of SLA one at a time (e.g. children vs. adults, instructed vs. naturalistic learning).

Our study is aimed at assessing the acquisition outcome of 6 English morphemes in the interlanguage of three members of an Indonesian family one year after they arrived in Australia. The 6 morphemes are: past tense -ed, plural -s, (stand-alone) $V$-ing form, $A u x+V$ forms including progressive be+V-ing, perfective have $+V-e n$, and Modal $+V$. Our goal is to find out how much English morphology the informants have acquired after one year of living and working/studying in the English-speaking environment. We are also interested to see the extent to which the acquisition outcome interacts with the settings in which the informants have learned or are learning L2 English. Our investigation is carried out within the framework of Processability Theory (Pienemann, 1998), in particular, its proposed universal L2 developmental sequence for English morphology (Pienemann, 1998, 2005; Bettoni and Di Biase, forthcoming).

\section{L2 MORPHOLOGICAL DEVELOPMENT}

L2 learning settings have been a significant variable in the study of second language acquisition. Ever since the developmental sequence studies of the early 1970s, researchers have been trying to find out if formal instruction could affect the route of L2 learning in any fundamental way. A large number of empirical studies show definitively that all learners follow the same developmental sequences and, for classroom students, the sequences are maintained regardless of the order in which they are taught (e.g. Pienemann, 1987). Learning settings affect the rate of learning and the overall accuracy of L2 production, with instructed learners in both foreign and second language settings progressing 
faster and being more accurate than naturalistic learners (e.g. Sato, 1990; Ellis, 1989; Jansen, 2008; Jia and Fuse, 2007).

To account for the L2 developmental sequences, Pienemann in his Processability Theory (PT) (1998) proposes that L2 learning is a process of developing processing routines for L2. The development is essentially learner-internal in that learners are only able to acquire L2 structures they are able to process. The influence of external factors such as formal instruction and learning settings is restricted to the rate and the ultimate attainment of the L2 development. The acquisition sequence does not alter, and the developmental stages cannot be skipped. At a particular developmental point, the interlanguage grammar is stable, if assessed through the 'emergence criterion' (Pienemann, 1998). To date, these claims have been supported by cross-linguistic empirical studies in L2 German, Japanese, Chinese, Italian, English, Swedish, to name a few (See Pienemann, 2005; Mansouri, 2007; Kessler, 2008).

One of the PT principles underlying the L2 developmental sequence for morphology is that of grammatical information exchange for agreement. Grammatical information refers to features (number, tense, person) and their values (+/-plural, +/-past, 1 st $/ 2 \mathrm{nd} / 3 \mathrm{rd}$ person) encoded in the lexicon. Information exchange is an operation in which the feature/value is unified (or exchanged) between two constituents for agreement purposes. In the example below, the grammatical information in the subject my father (+singular, +3 rd person) is exchanged with that in the verb such that the $3 \mathrm{rd}$ person singular morpheme $-s$ is inserted after the verb.

$\begin{array}{lll}\text { My father } & \text { smoke-s } & \text { every day. } \\ \text { +singular } & \text { +singular } & \text { +present (habitual) } \\ \text { +3rd person } & \text { +3rd person } & \\ & \text { +present }\end{array}$

As information exchange occurs at different levels of linguistic structures (in a phrase and across phrases), the operation poses different degrees of processing complexity. L2 learners need to develop their L2 processing skills progressively to handle operations of increasing complexity. Consequently, the capacity to process L2 linguistic material determines the acquisition outcome of L2 linguistic structures. Table 29.1 shows the processing procedures and the possible learning outcomes for each procedure.

Analysing English morphemes from this perspective, we can see that invariant forms (single words, formulaic expressions) at the initial stage do not involve any processing 
procedure as they are chunks or non-analysed material. Past tense marker - ed and V-ing form requires identification of the verb category of lexical items, while the plural $-s$ requires the analysis of the noun category. If plural $-s$ is associated with generic entities ( $I$ like bananas) or plural objects without modifiers (desks vs desk), no information exchange with another constituent takes place. However, if the plural feature appears in the head noun and its modifier(s) (these/many/three apples), this information needs to be unified across two lexical items in an NP.

Similarly, information exchange can occur within a VP between the auxiliaries (be, have, modal) and their lexical verbs (V-ing, $V-e n, V)$ to indicate grammatical aspects and modal. Finally, in the simple non-past context, the grammatical information (person, number) in the subject is transferred to the verb across the phrasal boundary (NPsubj and VP), and the outcome is the 3rd -s (Pienemann, 1998, 2005; Bettoni and Di Biase, forthcoming).

\begin{tabular}{|l|l|l|l|}
\hline Stage/Procedure & Outcome & Structure & Example \\
\hline 4. S-procedure & $\begin{array}{l}\text { Interphrasal } \\
\text { morphology }\end{array}$ & $3^{\text {rd }}$ person singular $-S$ & Peter loves rice \\
\hline 3. Phrasal & VP morphology & $\begin{array}{l}\text { Aux }+V \\
\text { Have }+V-\text {-en } \\
\text { Be }+V-\text {-ing } \\
\text { Modal }+V\end{array}$ & $\begin{array}{l}\text { They have walked } \\
\text { I am cooking } \\
\text { You can go now }\end{array}$ \\
& NP morphology & Phrasal plural $-s$ & $\begin{array}{l}\text { These girls } \\
\text { Many dogs } \\
\text { Three black cats }\end{array}$ \\
\hline 2. Category & Lexical morphology & $\begin{array}{l}\text { Past }- \text { ed } \\
\text { Plural }-s \\
\text { Verb -ing }\end{array}$ & $\begin{array}{l}\text { Mary jumped } \\
\text { I like apples } \\
\text { He working }\end{array}$ \\
\hline 1. Lemma & Invariant forms & $\begin{array}{l}\text { Single words } \\
\text { formulas }\end{array}$ & $\begin{array}{l}\text { Station, here } \\
\text { My name is Pim }\end{array}$ \\
\hline
\end{tabular}

Table 29.1 Developmental sequence for English morphology

Adapted from Pienemann (2005) and Bettoni and Di Biase (forthcoming).

Developmental sequences based on these operations are used to study the L2 acquisition process as well as assess L2 learning outcomes. In our study, the PT conceptual and 
analytical framework is employed to assess the acquisition outcome of the L2 English morphology. Taken into consideration our informants' age, their L2 English learning experience, length of stay in Australia, and level of exposure to and use (or practice) of English in Indonesia and Australia (details in the next section), we hypothesize that the entire English morphological system would have emerged although the accuracy rates would vary. We also hypothesize that the daughter would have outperformed both parents due to her young age and L2 instruction and immersion in Australian schools.

\section{METHOD}

\section{INFORMANTS}

The family came to Australia in January (the father) and February (the mother and the daughter) 2009 because the father was on a scholarship to pursue his Masters degree. In their early 30 s, both the father and the mother had received significant formal instruction in English in Indonesian schools (over 14 years). The father had also studied for four years in an international program in which the medium of instruction was English. Upon graduation in the late 1990s, he worked in the Indonesian public service for 11 years, using English from time to time, but had no exposure to English after work. His English proficiency upon arrival was fairly good, as evidenced by his overall IELTS score of 6.5. The mother did not use English in her work for 10 years, nor did she have any contact with English in the daily life. When she arrived in Australia, her ability to communicate in English was minimal, restricted to a few words and formulaic expressions. The daughter had no English at all.

In Australia, the family has full exposure to and contact with English. The father is a full-time postgraduate student, the mother works full-time in service encounter jobs that require communication with clients. The daughter went to pre-school for 7-months (4 hours/day and 3 days/week) before going to kindergarten (5 days/week for 3 months) where she attended English classes in the school's English Centre. Neither of her parents attended English classes in Australia. Table 29.2 is a summary of the English learning background of the informants.

The home language is Bahasa Indonesian. The family watches Australian TV programs every evening. Their non-Indonesian social circles include the priest in a local church and fellow churchgoers many of whom are English native speakers, but socializing occurs on Sunday only. On these occasions, though, the father does almost all the talking. Outside study and work, the family has little social contact with native speakers of English. The family travels extensively in Australia, enjoying what the country has to 
offer (picnics, animals, parkland, local cultural and social events and activities). Both parents like Australia and would love to stay longer. The daughter has mixed feelings: she likes what Australia has to offer (animals, theme parks), but does not want to stay because Australia is too expensive for her to keep pets, as she did in Indonesia.

\begin{tabular}{|l|l|l|l|}
\hline L2 Learning & Father & Mother & Daughter \\
\hline Formal EFL & $14 y$ rs & 14 yrs & - \\
\hline Formal ESL & - & - & $3 \mathrm{mths}$ \\
\hline Naturalistic & + & + & + \\
\hline $\begin{array}{l}\text { Exposure to English } \\
\text { in Indonesia }\end{array}$ & Sometimes in work & - & - \\
\hline $\begin{array}{l}\text { Exposure to English } \\
\text { in Australia }\end{array}$ & Full-time study & Full-time work & $\begin{array}{l}\text { Pre-school \& } \\
\text { kindergarten }\end{array}$ \\
\hline $\begin{array}{l}\text { English proficiency } \\
\text { on arrival }\end{array}$ & IELTS 6.5 & $\begin{array}{l}\text { Minimal (single } \\
\text { words, formulas) }\end{array}$ & None \\
\hline
\end{tabular}

Table 29.2 English learning background

\section{DATA ELICITATION METHODS}

The informants' L2 English speech data was collected individually through oral interviews at the informants' home. ${ }^{2}$ The interviewer, an Indonesian MA TESOL student, and the informants' family were friends, living in the same house in Australia. The close social relationship between the interviewer and the informants and the location of the interview provided abundant 'shared resources - linguistic, personal, cultural, and social' during the interview (Liddicoat, 1997, p. 314), and enabled the interaction to be more natural and the informants to be more cooperative. Data obtained this way tends to be more authentic and representative of the informants' true L2 level.

The interview followed a structured format, with the interviewer providing talking points and tasks specifically designed to elicit the targeted grammar forms. Table 29.3 presents the tasks, conversation topics and the grammatical forms being targeted. VP structures (have $+V-e n$, be $+V-i n g$, Modal $+V$ ) were not elicited consistently though. Following the method used in the well-known 'wug' test (Berko, 1958), a naming and counting task was used to elicit the plural $-s$ from the daughter (see Excerpt 29.1). Due to family circumstances, the mother and the daughter were interviewed twice, for a total 
of 26'25" (mother) and 36'20" (daughter) respectively. The father was interviewed three times, for a total of $21^{\prime} 40$ ".

Six weeks after the interview, we got together with the family for an informal chat. We used this opportunity to thank the informants, to confirm their background information, and to find out more details about various aspects of their language learning and social contacts in Australia. ${ }^{3}$

\begin{tabular}{|l|l|}
\hline Main talking points/tasks & Grammar points \\
\hline Everyday routines of mother/father/ daughter & $3^{\text {rd }}-s$ \\
\hline $\begin{array}{l}\text { - Yesterday's activities/events } \\
\text { - Holidays in the Gold Coast and Melbourne }\end{array}$ & past marker -ed \\
- Flu vaccination previous week & \\
- Family activities during Easter in Indonesia last year & \\
\hline - Picture description (parents) & progressive be+V-ing \\
- Naming and counting objects (daughter) & plural $-s$ \\
\hline
\end{tabular}

Table 29.3 Interview topics

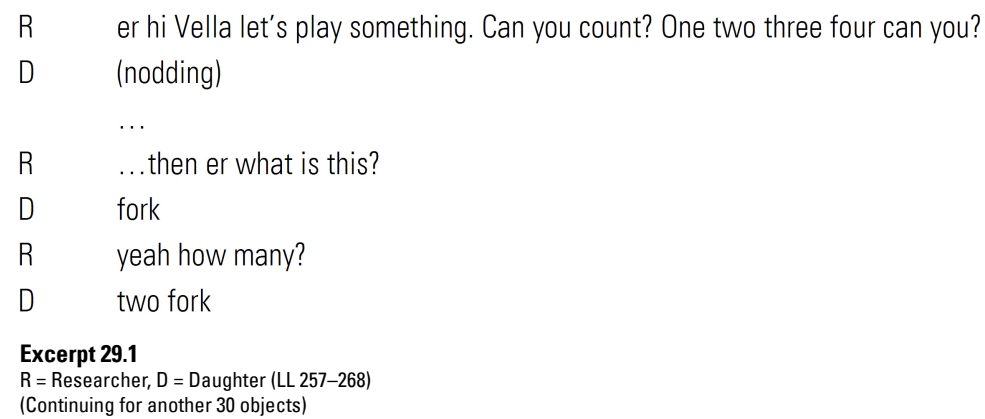

\section{DATA ANALYSIS}

The interviews were audio-recorded and transcribed. We tagged the nouns and the verbs with and without the required morphemes in their obligatory contexts. The tokens of the morpheme suppliance and the ratio between the suppliance and the obligatory context were worked out. For the stand-alone $V$-ing form, we simply counted the tokens. Similarly, we identified the occurrence of the three VP forms and checked for agreement 
between the auxiliaries and the forms of the corresponding main verb. Cases of over-suppliance (use of morphemes in non-obligatory contexts the clinics when there was one clinic) were also identified.

Next, we applied the acquisition criterion to the results of the quantitative analysis. We used two criteria: the emergence criterion and the accuracy criterion. The emergence criterion is defined as the first systematic and productive use or appearance of a form/structure (Pienemann, 1987, 1998). The first systematic use expresses 'a moment in interlanguage development in which there are signs of regular, constant use of the structure, but these are the "first" such signs,' whereas the productive use requires that 'at least some uses of the target morpheme are productive' (Pallotti, 2007, p. 367).

In the analysis, we took care to tease out the forms not complying with the 'productive use' and 'systematic distribution' (Pallotti, 2007, p. 371; see also Pienemann, 1998; Zhang, 2003). Specifically, we paid attention to the presence of lexical variation (apples-animals) and morphological variation (talks-talked). We set the emergence point at four tokens in obligatory contexts, and the tokens must exhibit lexical or morphological variations. Copying the interviewer's previous utterance(s) and self-repeating (can you go to can you go to...) were not included in the tally. ${ }^{4}$

The accuracy criterion is usually expressed in percentages, which is set arbitrarily by individual researchers without much theoretical reasons even though it is used to draw conclusions about acquisition (Pallotti, 2007). We used the accuracy criterion to gauge the extent of acquisition (or mastery) to complement the point of acquisition as measured by the emergence criterion. The accuracy criterion in our study was set at 80 per cent correct suppliance of the morphemes in obligatory contexts. ${ }^{5}$

\section{RESULTS}

The interview turned out to be effective in a number of ways: through various forms of prompts (questions, requests, pictures, objects), the interview provided many opportunities for the informants to supply the required morphemes. Table 29.4 displays the results. Corresponding to the grammatical morphemes listed in Column 2 are suppliances (tokens) before the slash, and their contexts after the slash. The ratio between the token and the context is given in brackets, and the over-suppliance is listed after the arrow sign ( $>$ ).

Applying the emergence criterion to the results (4 tokens in obligatory contexts + lexical or morphological variation), we draw the following conclusion: except for the past tense marker -ed, which did not emerge in the L2 English of any informants, 
a. all the targeted English morphology emerged in the L2 of the father

b. the NP morphology (lexical and phrasal plural $-s$ ) emerged in the L 2 of the mother

c. the lexical plural $-s$ emerged in the $\mathrm{L} 2$ of the daughter

d. the V-ing form was used only by the daughter

e. no over-suppliance was observed in the data of the daughter

f. the VP instances were not sufficient in the data of the mother and the daughter

The bordered areas in Table 29.4 indicate the current stages of the informants as measured by emergence criteria.

Based on the accuracy criterion of 80 per cent correct use of the morphemes in obligatory contexts, only the father attained the status of 'mastery,' and only for the NP morphology (the plural marking in the shaded area).

In the past context where the verb was not inflected for the past tense, the bare verb form was produced. In the case of the daughter, the $V$-ing form was also used in almost all contexts: past and non-past, and the 3rd person singular. Excerpt 2 is taken from the daughter's transcript. The $V$-ing forms are underlined, and the bare verb stems are in italics.

R Ehm...ok Vela ehm yesterday I talked with your mom and she said that your English's very good. I just want to know (laughing) so Vela can you tell me what does your mother usually do every day?

D ehmm (unclear) cooking and watching (unclear) and then cooking sleeping ehm sleep and (unclear) go to school.

R ...can you tell me what does your father usually do everyday?

D ehmm father ehm working after working he go home after go home eating and he sleep and he working again.

\section{Excerpt 29.2}

$\mathrm{R}=$ Researcher, $\mathrm{D}=$ Daughter (LL 1-13)

Judging from the L2 production data of our informants, the father attained the S-procedure (Stage 4) for English morphology, the mother reached the Phrasal Procedure Stage (3), and the daughter was at Stage 2 (Category Procedure). Within each informant as well as across the three informants, a hierarchical, implicational profile is observed: if a processing procedure at a higher stage has emerged in the data of the informant, the processing procedure(s) below it has also emerged, but the reverse is not true. This profile is in line with the general claims of PT as well as SLA developmental sequence literature. 


\begin{tabular}{|c|c|c|c|c|}
\hline Stage & Morpheme & Father & Mother & Daughter \\
\hline \multirow{3}{*}{$\begin{array}{l}\text { 2. Category } \\
\text { procedure } \\
\text { (lexical } \\
\text { morphology) }\end{array}$} & past-ed & $\begin{array}{l}{ }^{*} 2 / 9(.22) \\
>0\end{array}$ & $\begin{array}{l}{ }^{*} 0 / 12(.00) \\
>0\end{array}$ & $\begin{array}{l}{ }^{*} 0 / 6(.00) \\
>0\end{array}$ \\
\hline & V-ing & 0 & 1 & 20 \\
\hline & lexical pl-s & $\begin{array}{l}27 / 31(.87) \\
>3\end{array}$ & $\begin{array}{l}6 / 14(.43) \\
>1\end{array}$ & $\begin{array}{l}4 / 25(.16) \\
>0\end{array}$ \\
\hline \multirow{2}{*}{$\begin{array}{l}\text { 3. Phrasal } \\
\text { procedure } \\
\text { (NP, VP) }\end{array}$} & $\begin{array}{l}\text { NP: } \\
\text { phrasal pl-S }\end{array}$ & $\begin{array}{l}24 / 28(.86) \\
>2\end{array}$ & $\begin{array}{l}20 / 33(.61) \\
>0\end{array}$ & $\begin{array}{l}* 2 / 23(.09) \\
>0\end{array}$ \\
\hline & $\begin{array}{l}\text { VP: AUX+V } \\
\text { be+V-ing } \\
\text { have }+V-\text {-en } \\
\text { MOD+V }\end{array}$ & $\begin{array}{l}5 / 7(.71) \\
3 / 5 \\
/ \\
2 / 2\end{array}$ & $\begin{array}{l}* 2 / 2(1.0) \\
1 / 1 \\
(1 / 1) \\
1 / 1\end{array}$ & $\begin{array}{l}{ }^{*} 3 / 3(1.0) \\
1 / 1 \\
/ \\
2 / 2\end{array}$ \\
\hline $\begin{array}{l}\text { 4. S-procedure } \\
\text { (interphrasal } \\
\text { morphology) }\end{array}$ & $3^{r d}-s$ & $\begin{array}{l}14 / 19(.74) \\
>0\end{array}$ & $\begin{array}{l}{ }^{*} 2 / 17(.12) \\
>0\end{array}$ & $\begin{array}{l}{ }^{*} 1 / 40(.03) \\
>0\end{array}$ \\
\hline
\end{tabular}

Table 29.4 English learning background

* Non-emergence

\section{DISCUSSION}

The results comply with the developmental sequence for English morphology postulated in PT, supporting the view that second language acquisition proceeds incrementally in an orderly manner, constrained by L2 processing resources (Pienemann, 1998, 2005). The level of processing resources (procedures) the informants possess is related to the morphological forms they are able to acquire. Thus, the daughter, having developed the skill to analyze the grammatical categories of English lexical items, acquired lexical plural -s (girls, friends), and produced the stand-alone $V$-ing form but not morphological forms requiring other procedures at higher stages.

The results do not support our hypotheses. None of the informants acquired the entire English morphological system. They were at different developmental stages, with the 
father being the most advanced as judged on the basis of both emergence and accuracy criteria. The daughter did not outperform the parents according to these criteria.

Although we do not have any L2 data of the informants when they first arrived in Australia a year ago, we are fairly confident of their global L2 proficiency based on their self-report data and our knowledge of them. It is therefore not too far-fetched for us to claim that the father might have been at the level he is now a year ago, judging from his overall IELTS score (6.5) and his prior L2 learning and continuing access to English in Indonesia. However, the mother and the daughter started to develop their L2 in Australia. Although the mother, like the father, received abundant L2 English instruction in Indonesian schools, she did not use English for 10 years after graduation. Like any skill development where input and practice are indispensable (DeKeyser, 2007), a lack of input means 'new knowledge structures' (Kasper, 1997, p. 310) cannot be established, and a lack of practice contributes to the attrition of previously established L2 knowledge structures and skills. The difference in the level of L2 English morphology between the father and the mother is partly due to the difference in the continuing L2 exposure and practice after their formal education ended in Indonesia.

Once in Australia, exposure to and practice in English is not an issue anymore for the mother because she has been working full-time. Why did she fail to catch up with the father, after a whole year, in both acquisition and accuracy? Two factors might not have worked in her favour: her low level of English proficiency upon arrival and exclusive naturalistic L2 learning in Australia.

It seems that for adult L2ers, the level of proficiency one has already achieved upon arrival in the target language environment accounts for the rate of their subsequent L2 development (Schmidt, 1983). True beginners are unable to take advantage of the rich input in the naturalistic setting because they simply cannot understand most of the language around them (Krashen, 1982). Without comprehensible input, it is hard for the learner to develop a 'functional language faculty' (De Graaff and Housen, 2009, p. 729) to process L2 linguistic material necessary for acquisition. Although the mother is not a 'true beginner' (compared to her daughter) because of her years of formal EFL learning in Indonesia, her L2 contained all the features of a beginner when she first came to Australia. Judging by her own account, she was unable to understand and produce anything beyond a few words and formulaic chunks, typical of an L2 beginner and Stage 1 behavior.

The mother did not attend any English classes in Australia. Instead she was learning English through natural exposure in her work places. SLA literature (De Graaff and Housen, 2009) shows that for adult L2ers, learning in a pure naturalistic setting without 
any formal instruction including self-study, conscious attention to form, and conscious learning strategies does not result in accurate L2 and fast learning rates. Evidence from different types of research comparing formal L2 instruction with naturalistic exposure in both second and foreign language settings shows ' $\mathrm{L} 2$ instruction can make a difference in how (well) learners acquire a second language' (De Graaff and Housen, 2009, p. 726). Compared to naturalistic learners, instructed learners 'progress at a faster rate, ... are likely to progress further along the (developmental) sequences, and ... typically become more accurate overall' (Ortega, 2009, p. 100). Without the benefit of formal instruction in Australia, the mother's progress in L2 was negatively affected.

However, compared to her daughter, the mother has learned more and faster in a year although at the start of the year, both could hardly communicate in English. The fact that the mother received English instruction back in Indonesia albeit a long time ago might have turned out to be an advantage. According to Schmidt (1983), prior learning provides the learner with a body of knowledge to build upon and develops their sensitivity to forms to some extent. Although the daughter (for a period of 7 months) and the mother were both 'picking up' English naturalistically in Australia, the prior L2 learning by the mother distinguishes her as a beginner instead of an absolute beginner (the daughter). The former is characterized by having had exposure to L2 and therefore, possessing some latent L2 knowledge but not L2 skill, while the latter has never had any L2 exposure, hence, no L2 knowledge or skill. Early studies on naturalistic SLA reveal that increased proficiency without formal instruction involve learners who already had a substantial amount of formal instructions (Carroll, 1967; Upshur, 1968; Mason, 1971; Schmidt, 1983). Faster and more accurate L2 learning by the mother than the daughter could be due to her prior EFL experience.

Of the three members of the family, the daughter has acquired the least amount of English morphology in a year even though she has the advantage of her young age and some formal ESL instruction in an Australian school (3 months). Age-related SLA literature generally shows an advantage for younger learners in terms of ultimate attainment, but not in terms of the initial rate (Krashen, Long and Scarcella, 1979; Hyltenstam and Abramhamsson, 2003). Longitudinal naturalistic data from young L2ers revealed that it usually takes months for certain aspects of L2 grammar to be acquired (Pienemann, 1987; Jia and Fuse, 2007). In view of the fact that the L2 exposure period was one year and for much of that period ( 7 months) the daughter was uninstructed and not fully immersed (4 hours/day and 3 days/week), it is perhaps not unusual for the daughter to be still at the initial point of English morphology after a year. The naturalistic exposure 
and 3-month formal instruction was neither intense nor long enough for a 5-year-old child to learn more than she did.

The one nagging gap in the acquisition outcome in Table 29.4 is the past tense marking on regular verbs, a Stage 2 form. None of the informants have reached the emergence point for it although the data of the father and the mother are robust in irregular past forms of verbs. A Similar phenomenon has been observed in the L2 English literature (Lardiere, 1998a, 1998b, 2000; Hawkins and Liszka, 2003; Jia and Fuse, 2007; Schmidt, 1983; Zhang, Liu and Bower, in preparation). These L2ers were either advanced learners in their end-state of SLA, or were learning English naturalistically. Classroom learners, on the other hand, show high rates of accuracy in the use of $-e d$ (Bardovi-Harlig, 1995), possibly as a function of written tasks. While the source of the -ed problem is not the focus of our study, we would like to mention that the issue has been explored in terms of the learners' L2 morphological knowledge (Beck, 1997), morphological competence, i.e. skill to map/assemble grammatical features (Lardiere, 2000), L1 transfer (Hawkins and Liszka, 2003), and formal L2 training (Zhang, Liu and Bower, in preparation). The existing evidence suggests that simply being exposed to L2 in the target language environment and using L2 for communication does not seem to aid robust acquisition of the past tense $-e d$ by learners of certain L1 backgrounds, like Chinese. As Bahasa Indonesian does not mark past time reference morphologically either, Indonesian- English learners may experience the same problems acquiring $-e d$ as Chinese-English L2ers.

\section{CONCLUSION}

In this study, we investigated the acquisition outcome of English morphology in the L2 English of three members of an Indonesian family. Despite one year of living, working or studying in Australia, none of the informants have acquired the full range of English morphology, and only the father has reached 80 per cent accuracy level for one morpheme: the plural $-s$. The developmental sequence for English morphology stated in Pienemann (2005) is maintained, suggesting that SLA is essentially a cognitive process constrained by an internal processing mechanism.

Contextualizing the acquisition outcome against the settings surrounding the informants' L2 learning (EFL, ESL, naturalistic exposure), our findings corroborate other studies in that 1) the higher one's L2 proficiency level is at the time of arrival in the target language environment, the more beneficial the environment is for the learner to further develop her L2; 2) mere exposure does not give the learner the advantage in the rate of 
L2 morphology development; 3) formal instruction is helpful in promoting a faster and more accurate learning outcome for adult L2 learners.

Our study is limited in scope so that a fuller developmental profile of the informants cannot be established. As the informants will be staying in Australia for another 8 months from the time of the interview, we plan to continue to collect data so as to see further development in their L2 morphology system in naturalistic (mother) and naturalistic plus formal instruction (the daughter) settings.

\section{ACKNOWLEDGEMENT}

We wish to express our gratitude to the informants for their time and willingness to participate in this study. We would also like to thank all students in the unit Research Projects in Language Teaching and Learning for discussions and comments at various stages of the study. We are grateful to Sue Wharton who eliminated the non-native features in the paper. Last but not least, we wish to thank the editor and the anonymous reviewer for their comments and suggestions on an earlier draft of the paper. We take full responsibility for the errors that remain.

\section{ENDNOTES}

The information was supplied by the informants, They read this section and confirmed the accuracy of the information being presented.

Informed consent was obtained.

We talked about their life and work in Indonesia and Australia, the mother's work and language learning experience in Indonesia and Australia, and the daughter's experience in Australia schools.

We did not count the plural noun toys in the daughter's data because unlike girls, friends, the word toy in everyday use tends to be in the plural form. The daughter produced it in the plural form only.

Different accuracy criteria are found in SLA studies ranging from 60 per cent to 90 per cent correct use of a particular form or structure. For a full discussion of acquisition criteria, see Pallotti (2007). 


\section{REFERENCES}

Bardovi-Harlig, Kathleen. (1995). The interaction of pedagogy and natural sequences in the acquisition of tense and aspect. In F. Eckman, D. Highland, P. Lee, J. Mileham and R. Weber (Eds.), Second language acquisition theory and pedagogy (pp. 151-168). Mahwah, NJ: Lawrence Erlbaum.

Beck, Maria-Luise. (1997). Regular verbs, past tense and frequency: Tracking down a potential source of NS/NNS competence differences. Second Language Research, 13, 93-115.

Berko, Jean. (1958). The child's learning of English morphology. Word, 14, 150-177.

Bettoni, Camilla; Di Biase, Bruno. (Forthcoming). Processability Thoery and its theoretical bases. To appear in B. Di Biase and C. Bettoni (Eds.), Processability Theory: Current issues in theory and application. Amsterdam: John Benjamins.

Carroll, John. (1967). Foreign language proficiency levels attained by language majors near graduation from college. Foreign Language Annals, 1, 131-151.

De Graaff, Rick; Housen, Alex. (2009). Investigating effects and effectiveness of L2 instruction. In M. Long and C. Doughty (Eds.), The handbook of language teaching (pp. 726-753). Oxford: Wiley-Blackwell.

Dekeyser, Robert. (2007). Skill acquisition theory. In B. van Pattern and J. Williams (Eds.). Theories in second language acquisition (pp. 97-14). Lawrence Erlbaum.

Ellis, Rod. (1989). Are classroom and naturalistic acquisition the same? A study of the classroom acquisition of German word order rules. Studies in Second Language Acquisition, 11, 305-328.

Hawkins, Roger; Liszka, Sarah. (2003). Locating the source of defective past tense marking in advanced L2 English speakers. In R. van Hout, A. Hulk, F. Kuiken and R. Towell (Eds.), The Lexicon-syntax interface in second language acquisition (pp. 21-44). Amsterdam: John Benjamins.

Hyltenstam, Kenneth; Abrahamsson, Niclas. (2003). Maturational constraints in SLA. In C. Doughty and M. Long (Eds.), The handbook of second language acquisition (pp. 539-588). Oxford: Blackwell.

Jansen, Louise. (2008). Acquisition of German word order in tutored learners: A cross-sectional study in a wider theoretical context. Language Learning, 58, 185-231.

Jia, Gisela; Fuse, Akiko. (2007). Acquisition of English grammatical morphology by native Mandarin-speaking children and adolescents: Age-related differences. Journal of Speech, Language and Hearing Research, 50, 1280-1299.

Kasper, Gabriele. (1997). "A" stands for acquisition: A response to Firth and Wagner. The Modern Language Journal, 81, 307-312.

Kessler, Jeorg. (Ed.). (2008). Processability approaches to second language development and second language learning. Newcastle: Cambridge Scholars Press.

Krashen, Stephen. (1982). Principles and practice in second language acquisition. New York: Pergamon Press. 
Krashen, Stephen; Long, Michael; Scarcella, Roger. (1979). Age, rate and eventual attainment in second language acquisition. TESOL Quarterly, 13, 573-582.

Lardiere, Donna. (1998a). Case and tense in the 'fossilized' steady state. Second Language Research, 14(1), 1-26.

Lardiere, Donna. (1998b). Dissociating syntax from morphology in a divergent L2 end-state grammar. Second Language Research, 14, 359-375.

Lardiere, Donna. (2000). Mapping features to forms in second language acquisition. In J. Archibald (Ed.), Second language acquisition and linguistic theory (pp.102-129). Oxford: Blackwell.

Liddicoat, Anthony. (1997). Interaction, social structure, and second language use: A response to Firth and Wagner. The Modern Language Journal, 81, 313-317.

Mansouri, Fethi. (Ed.). (2007). Second language research theory-construction and testing. Newcastle: Cambridge Scholars Press.

Mason, Charles. (1971). The relevance of intensive training in English as a foreign language for university students. Language Learning, 21, 197-204.

Ortega, Lourdes. (2009). Sequences and processes in language learning. In M. Long and C. Doughty (Eds.). The handbook of language teaching (pp. 81-105). Oxford: Wiley-Blackwell.

Pallotti, Gabriele. (2007). An operational definition of the emergence criterion. Applied Linguistics, 28, 361-382.

Pienemann, Manfred. (1987). Psychological constraints on the teachability of language. In C. Pfaff (Ed.), First and second language acquisition processes (pp. 146-168). New Book: Newbury House.

Pienemann, Manfred. (1998). Language processing and second language development: Processability Theory. Amsterdam: John Benjamins.

Pienemann, Manfred. (2005). An introduction to Processability Theory. In M. Pienemann (Ed.), Cross-linguistic aspects of Processability Theory (pp. 1-60). Amsterdam John Benjamins.

Sato, Charlene. (1990). The syntax of conversation in interlanguage development. Tubingen: Gunter Narr.

Schmidt, Richard. (1983). Interaction, acculturation, and the acquisition of communicative competence: A case study of an adult. In N. Wolfson and E. Judd (Eds.), Sociolinguistics and language acquisition (pp. 137-174). Rowley, MA.: Newbury House.

Siegel, Jeff. (2003). Social context. In C. Doughty and M. Long (Eds.), The handbook of second language acquisition (pp. 179-223). Oxford: Blackwell.

Upshur, John. (1968). Four experiments on the relation between foreign language teaching and learning. Language Learning, 18, 111-124. 
Zhang, Yanyin. (2003). A note on the accuracy criterion and the emergence criterion. Chinese Teaching in the World [in Chinese], 65 (3), 52-60.

Zhang, Yanyin; Liu, Bo; Bower, Eileen. (in preparation). Nature or nurture? Past tense marking by advanced Chinese speakers of L2 English.

Cite this article as: Zhang, Yanyin; Widyastuti, Ima. (2010). 'Acquisition of L2 English morphology: A family case study'. Australian Review of Applied Linguistics 33 (3), 29.1-29.17. DOI: 10.2104/aral1029. 